\title{
Translation and testing of measurement properties of the Swedish version of the IKDC subjective knee form
}

Hanna Tigerstrand Grevnerts, K. Gravare Silbernagel, Sofi Sonesson, Clare Ardern, Annika Österberg, Håkan Gauffin and J oanna Kvist

The self-archived version of this journal article is available at Linköping University Electronic Press:

http:// urn.kb.se/ resolve?urn=urn:nbn:se:liu:diva-137085

N.B.: When citing this work, cite the original publication.

Tigerstrand Grevnerts, H., Gravare Silbernagel, K., Sonesson, S., Ardern, C., Österberg, A., Gauffin, H., Kvist, J ., (2017), Translation and testing of measurement properties of the Swedish version of the IKDC subjective knee form, Scandinavian J ournal of Medicine and Science in Sports, 27(5), 554-562. https:// dx.doi.org/ 10.1111/ sms.12861

Original publication available at:

https:/ / dx.doi.org/ 10.1111/ sms. 12861

Copyright: Wiley: 12 months

http:/ / eu.wiley.com/WileyCDA/ 


\section{Translation and testing of measurement properties of the Swedish version of the IKDC subjective knee form}

Running title: The Swedish IKDC subjective knee form

\section{Authors:}

Authors:

1. First name: Hanna

Last name: Tigerstrand Grevnerts

Degree: PT, MSc

Affiliation: Rorelse och Halsa, Primary Healthcare rehabilitation, Region Ostergotland;

Division of Physiotherapy,

Department of Medical and Health Sciences, Linkoping University

2. First name: Karin

Last name: Grävare Silbernagel

Degree: PT, PhD, ATC

Affiliation: Department of Physical Therapy, University of Delaware,

3. First name: Sofi

Last name: Sonesson

Degree: PT, PhD

Affiliation: Division of Physiotherapy,

Department of Medical and Health Sciences, Linköping University

4. First name: Clare

Last name: Ardern

Degree: PT, PhD

Aspetar Orthopaedic \& Sports Medicine Hospital, Doha, Qatar; Division of Physiotherapy, Department of Medical and Health Sciences, Linköping University, Linköping, Sweden,

5. First name: Annika

Last name: Österberg

Degree: PT, MSc 
Affiliation: Centre for Clinical Research Sormland, Uppsala University, Eskilstuna, Sweden; Division of Physiotherapy, Department of Medical and Health Sciences, Linköping University

6. First name: Håkan

Last name: Gauffin

Degree: Orthopedic Surgeon, PhD

Affiliation: Orthopaedic Department, Linköping University; Department of Clinical and Experimental Medicine, Linköping University

7. First name: Joanna

Last name: Kvist

Degree: PT, Professor

Affiliation: Division of Physiotherapy, Department of Medical and Health Sciences, Linkoping University

\section{Corresponding Author:}

Joanna Kvist: Joanna.kvist@liu.se

Phone: 004613284664

Fax: 004613149403

Address: Joanna Kvist, Linkoping University, Div of Physiotherapy, Department of Medical and Health Sciences, 58183 Linkoping 


\begin{abstract}
Purpose: To translate to Swedish language and cross-culturally adapt the IKDC-SKF, and test the measurement properties of the Swedish version of IKDC-SKF in ACL-injured patients undergoing reconstruction surgery.
\end{abstract}

Methods: The translation and cross-cultural adaption was performed according to guidelines. 76 patients with an $A C L$ injury filled out the IKDC-SKF and other questionnaires before $A C L$ reconstruction and at 4, 6 and 12 months after surgery. 203 patients from the Swedish ACL-Registry, participated at 8 months post-operative. Measurement properties were tested according to the COnsensus-based Standards for the selection of health Measurement INstruments (COSMIN) guidelines.

Results: The Swedish IKDC-SKF had high internal consistency (Cronbach's alpha=0.90) and test retest reliability $\left(\mathrm{ICC}_{2,1}=0.92, \mathrm{Cl} 95 \%\right.$ : $\left.0.81-0.97, \mathrm{P}<.001\right)$. A single factor solution accounted for $46.1 \%$ of the variance in IKDC-SKF scores. Criterion validity was moderate to high. All ten predefined hypotheses for hypothesis testing were confirmed. The six hypotheses for responsiveness testing were confirmed. The effect size was 1.8 and the standardized response mean was 1.9 , the Minimal Clinically Important Difference was 13.9 points.

Conclusion: The Swedish version of the IKDC-SKF had good measurement properties and can be recommended for use in a population of $A C L$ deficient patients undergoing $A C L$ reconstruction.

Keywords: Patient reported outcome, knee surgery, ACL injury, ACL reconstruction 


\section{Introduction}

Evaluation of symptoms, function and sports participation during the rehabilitation phase after $A C L$ injury is of importance to monitor treatment and progression, and to evaluate the outcome. The most frequently used patient-reported outcome in ACL reconstruction populations worldwide is the International Knee Documentation Committee Subjective Knee Form (IKDC-SKF) (Wera et al., 2014). The IKDC-SKF is a 19-item, knee-specific, patientreported outcome, that measures symptoms, function and physical activity. Answers are provided in a five-point Likert scale (item 1, 4, 5, 7 - 17), 0-10 rating scale (item 2, 3, 18, 19) and dichotomous (item 6). The possible score ranging from 0-100 (calculated on 18 items since item 19 refers to knee function before injury), with a higher score indicating less symptoms, better function and a higher level of sports activity (Irrgang et al., 2001). The IKDC-SKF has been translated from the original English version to several languages, and the versions that meet the standards for translation process can be found at the webpage of the American Orthopaedic Society for Sports Medicine; www.sportsmed.org. The measurement properties of the original version of the IKDC-SKF have been tested extensively and showed to be good (Grevnerts et al., 2014), but measurement properties of the Swedish version of the IKDC-SKF have not been established.

The aim of this study was to perform translational and cross-cultural adaption for the Swedish version of the IKDC-SKF, and to test the validity, reliability, responsiveness and interpretability (floor and ceiling effect and Minimal Clinical Important Difference) of the IKDC-SKF in patients with an ACL injury undergoing reconstruction surgery, from before reconstruction to up to 1 year follow up. 


\section{Material and methods}

\section{Translation procedure}

The translation of the IKDC was completed according to the guidelines by Guillemin et al (1993). In the assessment of the measurement properties of the Swedish version of the IKDC, we followed the COnsensus-based Standards for the selection of health Measurement INstruments (COSMIN) guidelines, and the taxonomy, terminology and definitions for measurement properties developed by the COSMIN group (Mokkink et al. 2006; Mokkink et al., 2010).

The English version was first translated to Swedish by a physiotherapist and researcher experienced in ACL rehabilitation. The accordance of the translations was examined by two physiotherapist researchers and then translated back to English by a professional translator. The back-translation was compared to the original version, by the three physiotherapist researchers, to ensure consistency. An expert panel from different locations in Sweden consisting of two orthopedic surgeons who perform the majority of the $\mathrm{ACL}$ reconstructions in Sweden and four research physiotherapists experienced in knee injuries and experienced in writing in English, examined the Swedish version and commented on it. Comments on the translation were discussed thoroughly with other orthopedic surgeons and physiotherapists as well as with the developer of IKDC-SKF. The Swedish version of the IKDC-SKF was discussed in the expert panel before consensus was reached.

Cross-cultural adaption 
Two cultural adaptions were made: (i) "basketball" was changed to "handball or floorball", because these sports are more common in Sweden; (ii) the term "skiing" was clarified to "alpine skiing", to distinguish it from cross-country skiing.

\section{Face validity testing}

Ten patients with an ACL injury (age ranging from 17-38 years, 5 females) tested the Swedish and English version of the IKDC-SKF. All participants were active in sports before injury and nine were active in sport or rehabilitation at the time of completing IKDC-SKF. Six patients had had an ACL reconstruction and four had not. The first five patients were interviewed after filling out the questionnaire, and their opinions lead to minor changes in the form (how the term "pivoting" and "giving way" should be translated into Swedish). The remaining five patients were asked if they thought the questions in the Swedish version corresponded to the questions in the English version of the IKDC-SKF. All patients stated that the versions were similar and that the questions were relevant. The scores the patients showed on the Swedish and English forms were coherent.

The translation and cross-cultural adaption process together with face validity testing resulted in the final Swedish version of the IKDC-SKF.

\section{Data Collection}

Patients with an ACL-injury, aged 16-45 years old, and who had been wait-listed for an ACL reconstruction, were invited to participate during January 2012 to August 2013. They were recruited from four different orthopaedic clinics in Sweden.

Questionnaires were sent to the participants approximately 4 weeks prior to their surgery, for baseline measurement. Participants could choose between answering the questionnaires 
on paper and return in a prepaid envelope or log in to a web based system to complete an electronic version of the questionnaire. The questionnaire was sent again at 4, 6, and 12 months after surgery. For reliability testing, the form was sent again 5 days after the 6 months follow-up, to participants that completed the questionnaire at 6 months. Reminders were sent after 3 and 6 days to participants who had not responded.

Additionally, participants from the Swedish National ACL register who had undergone an $A C L$ reconstruction 8 months earlier, were asked to participate by filling out the questionnaire and sending it back in a prepaid envelope.

\section{Participants recruited from orthopaedic clinics}

A total of 179 patients who were on the waiting list for $A C L$ reconstruction were asked to participate. Seventy-six patients (42\%) accepted (table 1). The mean age of participants was 25 years (SD 8, range 16-45 years) and there was equal numbers of men and women (37 of 76 were female, $49 \%$ ). Six patients (6 of $76,8 \%$ ) had a revision of $A C L$ reconstruction. One participant was excluded from baseline evaluation, two were excluded from 4-month evaluation group, and one was excluded from 12-month evaluation group due to the omission of three or more items of the IKDC. The majority of patients ( 72 of $76,95 \%)$ reported that they were physically active before their $\mathrm{ACL}$ injury.

Participants recruited from the Swedish National ACL registry

All patients from the Swedish National ACL Registry who were asked to participate had undergone primary $\mathrm{ACL}$ reconstruction at a mean of 8 months earlier. Of 514 eligible patients, 203 (39\%) agreed to participate. There were 102 men (50\%), with a mean age of 24 years (SD 9 years, range $15-45$ years). Four participants ( $2 \%$ of 203 ) were excluded due to omission of three or more items of the IKDC-SKF. Twenty-one participants (10\% of 203) had 
had a previous contralateral $A C L$ reconstruction. The majority reported that they were physically active before injury (195 of $203,96 \%)$ and at the time of completing the IKDC-SKF (189 of $203,93 \%)$.

\section{Questionnaire package}

The questionnaire package contained the IKDC-SKF, the Knee Injury and Osteoarthritis Outcome Score (KOOS) (Roos, Toksvig-Larsen, 2003), the Short-Form 36 health survey questionnaire (SF-36) (Mohtadi, 1998; Sullivan et al., 1995; Persson et al., 1998; Sullivan and Karlsson, 1998), the ACL Return to Sport after Injury scale (ACL-RSI) (Kvist et al., 2012) (Table 2) and a Global Rating of Change (GRC) question (Kamper et al., 2009) with response options "fully recovered", "great improvement but not fully recovered", "some improvement but not fully recovered", "unchanged", "some deterioration", "great deterioration". Some study specific questions were used to evaluate satisfaction with knee function ("If you were to spend the rest of your life with knee function just the way it has been the last week, would you feel..."; response options: happy, satisfied, mostly satisfied, mixed feelings, mostly dissatisfied, dissatisfied and unhappy) and knee stability ("how stable do you consider your knee in activities of daily living" and "how stable do you consider your knee in exercise and sports" response options in a 10-point scale).

Data from Swedish National ACL Registry population, and patients from the clinics at 6 months after reconstruction were merged in the analysis of internal consistency, structural validity and criterion validity. Data from patients recruited from clinics were used for the reliability testing, using measurements taken at 6 months follow-up and again 5 to 21 days later. For responsiveness hypothesis testing the change score from baseline and 4 months and from baseline and 12 months was used. Minimal Clinically Important Difference (MCID) 
was assessed with the baseline and 4 month follow-up data. Floor and ceiling effects were evaluated at all measurement occasions.

All participant got written and verbal information of the study and gave their written consent to participate before study initiation. The study was approved by the Ethical Review Board in Linkoping, Dnr: 2011 450-31.

\section{Measurement properties that were evaluated: Reliability}

Internal consistency

Internal consistency is the extent to which items in a questionnaire are correlated, thus measuring the same concept (Mokkink et al., 2010). A Cronbach's alpha value between 0.7 and 0.95 is considered to show good internal consistency (Terwee et al., 2007).

Test-retest reliability

Test-retest reliability is the extent to which scores are the same across repeated measurements in patients whose health status has not changed (Mokkink et al., 2010). The time from test to re-test (5-21 days) was chosen to minimize the risk for patients to have a change in symptoms between measures, but were still long enough for them not to recall their previous answers. Forty-one patients filled out the form for test-retest analysis; responses from 13 patients were excluded because there was more than 21 days between measurement occasions, to avoid changes in their physical knee condition. Therefore, data from 28 patients were included in the analysis and they scored an IKDC-SKF mean of 60 (SD 17.6, 95\% Confidence Interval 53.1-66.7) at the first measurement and 63 (SD 17.8, 95\% 
Confidence Interval 56.1-69.9) at the re-test measure. None of the included patients reported new injury that affected their knee during the time between tests.

Test-retest reliability was assessed with a two-way random intraclass correlation coefficient $\left(I_{2.1}\right)$ for absolute agreement. An ICC value of $>0.9$ was considered to reflect excellent testretest reliability (Kline, 1999).

\section{Measurement error}

Standard error of measurement with included systematic differences (SEM agreement) was calculated using the change score from 6 months to Reliability testing measures, with the formula: $\mathrm{SD}_{\text {diff }} / \mathrm{V} 2$ (Hopkins, 2000). The smallest detectable change (SDC) was calculated for both individuals $\left(\mathrm{SDC}_{\text {ind }}=1.96 \times \sqrt{ } 2 \times \mathrm{SEM}\right)$ and groups $\left(\mathrm{SDC}_{\text {group }}=\mathrm{SDC}_{\text {ind }} / \mathrm{Vn}\right)($ Beaton, 2000 ; Terwee et al., 2007).

\section{Measurement properties that were evaluated: Validity}

\section{Structural validity}

Structural validity is the extent to which the items of a scale fit together and reflect the construct that is being measured (Terwee et al., 2007). Structural validity was assessed with an exploratory factor analysis using a principal component model and varimax rotation.

\section{Criterion validity}

Criterion validity is the extent to which the scores of the measurement instrument examined correlates to the score of a gold standard (Terwee et al., 2007). Criterion validity was tested using Short Form 36 (SF36) as a gold standard. We hypothesised that the IKDC-SKF would 
correlate more strongly ( $r>0.5)$ to the physical component summary (PCS) of the SF36 than to the mental component summary (MCS) $(r<0.5)$.

Hypothesis testing

Hypothesis testing is part of testing construct validity. Confirmation of $75 \%$ hypotheses is considered to reflect good hypothesis testing as a measurement property (Terwee et al., 2007).

Ten predefined hypotheses were specified by the authors, all with the predefined hypothesised magnitude of $r>0.5$. The hypotheses were tested with a Pearson's correlation test or Spearman rho correlation test as appropriate.

\section{Measurement properties that were evaluated: Responsiveness}

Responsiveness is the ability of an outcome measure to detect change over time in the construct being measured (Mokkink et al., 2010). Responsiveness was tested with both a criterion and construct approach (de Vet et al., 2011).

Criterion approach. We used the Global Rating of Change (GRC) as a gold criterion, with the answers dichotomized to either "no change" or "improved" compared to baseline. For the "no change" group, we included patients who reported "unchanged" or "some improvement but not fully recovered" on the GRC. For the "improved group" we included patients who reported "great improvement but not fully recovered" or "fully recovered" on the GRC (de Vet et al., 2011). We used the change of IKDC-SKF and GRC score from baseline to 4 months to test responsiveness. At that time we would expect some patients to be significantly improved in condition and some not, and we considered it was sufficient time for patients to recall whether a change in function had occurred. A Receiver Operating Characteristics (ROC) curve was plotted with the sensitivity and specificity for each possible change in score, and 
the Area under the Curve (AUC) was used to interpret the possibility for the IKDC-SKF to detect change in the patient-reported outcome. An AUC of $>0.70$ is considered adequate (Terwee et al., 2007).

Construct approach. We tested the correlations between IKDC-SKF change score to the change score of the five subscales of KOOS and the PCS of SF36. We used the change scores from baseline to 4-months and, to evaluate responsiveness for a longer follow-up timeframe, from baseline to 12-months. The time intervals were chosen since it was considered sufficient time for patients to be changed in their condition, compared to baseline.

The Effect Size (ES) and Standardized Response Mean (SRM) were calculated for change from before reconstruction to 12 months after, using the mean change scores divided by the standard deviation of scores from before reconstruction for ES, and mean change scores divided by the standard deviation of the change of scores for SRM (de Vet et al., 2011).

\section{Measurement properties that were evaluated: Interpretability}

Interpretability is not considered a measurement property, but regarded as important for the interpretation of the score. To evaluate interpretability, we examined two aspects: (i) floor- and ceiling effect ( 0 and 100 points score respectively), where below 15\% for either was considered acceptable (Terwee et al., 2007) and (ii) Minimal Clinically Important Difference (MCID).

MCID was determined by analyzing the ROC curve from responsiveness testing with data from 4 months. The score that was the closest to the left upper corner in the curve, was taken as the value on the IKDC-SKF that, at 4 months after $A C L$ reconstruction, best 
distinguished a patient who reported improvement from a patient who reported no change. This value corresponds to the highest sensitivity and specificity. We used the Youden index (Fluss et al., 2005; Youden, 1950) to calculate the value of MCID.

\section{Statistical analyses}

All analyses were performed using SPSS version 22. The IKDC-SKF data from each measurement occasion were handled in accordance to recommendations for scores, where up to two items missing is acceptable. Total scores for the IKDC-SKF were calculated using the equation (sum of the completed items)/ (maximum possible sum of the completed items) * 100, which gives a score from 0-100. 


\section{Results}

\section{Reliability}

Internal consistency was good; 0.9 , as measured with Cronbach's alpha. The test-retest reliability was excellent, with an $\mathrm{ICC}_{2,1}$ of 0.92 (Confidence Interval $95 \%$ : $0.81-0.97, \mathrm{P}<.001$ ). The SEM was 5.7 points, SDC group was 2.4 points and SDC $_{\text {ind }}$ was 15.8 points.

\section{Validity}

\section{Structural validity}

A single factor solution accounted for $46.1 \%$ of the variance. Factor loadings were $>0.4$ for 17 out of 18 items. The factor loading for item 6 ("during the past 4 weeks, or since your injury, did your knee lock or catch?") was 0.349 .

\section{Criterion validity}

There was a positive correlation between IKDC-SKF and the SF36. The correlation between the IKDC-SKF and the PCS was high, $r=0.73(p<0.001)$. There was a weak correlation between the IKDC-SKF and the MCS $r=0.32(p<0.001)$, confirming the hypothesis for criterion validity.

Hypothesis testing

All hypotheses were confirmed (Table 3). 


\section{Responsiveness}

The IKDC-SKF change score from baseline to 4 months was positively correlated with the global rating of change $(G R C)$ question $(r=0.62, p<0.01)$. Twenty-three participants were dichotomized to the "improved" group and 24 to the "not improved" group (Table 4). There were no patients reporting "fully recovered" or "unchanged". The ROC analysis showed an AUC of 0.79 (Figure. 1). Patients who reported "great improvement but not fully recovered" on the GRC had a mean change in IKDC-SKF from baseline to 4 months of 16.2 points of the IKDC-SKF (Table 4).

Correlations between change in score from baseline to 4 months and baseline to 12 months, showed a correlation greater than 0.5 for all hypotheses, thus confirming them all (Table 5). The effect size of the change from baseline to 12 months was 1.8 and standardized response mean was 1.9.

\section{Interpretability}

There was $1 \%$ ceiling effect at 6 - and 8 -months and $2 \%$ ceiling effect at 12 -months. The other measurement occasions showed no floor or ceiling effect.

The MCID calculated with score from 4 months was 13.9 points; with a sensitivity of $65.2 \%$ and a specificity of $95.5 \%$ (Figure. 1). 


\section{Discussion}

The Swedish version of the IKDC-SKF was shown to be reliable, valid and responsive to change in patients with an $A C L$ injury undergoing $A C L$ reconstruction. We followed the COSMIN guidelines (Mokkink et al., 2006; Mokkink et al 2010), and the questionnaire was translated and adapted to Swedish in several steps including forward and backwards translation, expert committee review, and pre-testing as recommended (Guillemin et al., 1993). The cross-cultural changes made ("basketball" was changed to "handball or floorball", "skiing" was clarified to "alpine skiing") were similar to cultural adaptions made in the Brazilian translation processes, where "skiing" was replaced with "surfing" (Metsavaht et al., 2010). Patients who completed both the Swedish and English version of the IKDC-SKF found both versions equivalent, which was supported by the equality of scores for both questionnaires.

The IKDC-SKF has a relatively low number of items compared to other similar forms (e.g. KOOS which has 42 items) and high internal consistency (Cronbach's alpha 0.90), suggesting that there is limited redundancy in the scale. The high test re-test reliability $\left(\operatorname{ICC}_{2,1}=0.92\right)$, is in accordance with previous studies on the English version (Irrgang et al., 2001; Kocher et al., 2011; Schmitt et al., 2010).

The SEM value (5.7 points) is comparable to previous studies (Irrgang et al., 2001; Greco et al., 2010; van Meer et al., 2013), and the SDC ind of 15.8 points indicates that a change in score in an individual patient should be above 15.8 points to be sure of a true change in condition. The result of $\mathrm{SDC}_{\text {ind }}$ is similar to the MCID (13.9 points) and although the values are taken from different times after $A C L$ reconstruction (the SDC is from the reliability testing six months after reconstruction and $\mathrm{MCIC}$ is the change value from baseline to four 
months after reconstruction), it might indicate an approximate magnitude of change of score needed to consider the change both "real" (not due to measurement error) and meaningful. The SDC group for a group of patients is much lower than the $\mathrm{SDC}_{\text {ind, }}$, i.e. 2.4 points, and is often the value used in research, where individual comparisons are less common. The discrepancy between the SDC group and MCID may suggest that even though a change has occurred in a group, it might not be enough to reflect change in condition for the individual patient.

The value of MCID is debated, and should be interpreted carefully since it is not a fixed attribute; it may change depending on what is important for the patient (Wang et al., 2011). The MCID could also be a reflection of the patient's satisfaction with his or her current knee function rather than the change from baseline, since it can be difficult for patients to recall change over time (Wright et al., 2012). The time frame is important when determining MCID, since it should be long enough for a clinically importantly changed to have occurred, but short enough for patients to remember if there has been a change or not.

The single factor solution from the analysis for structural validity indicates that the form is one dimensional and supports previous suggestions that the IKDC-SKF should be reported as one overall score (Irrgang et al., 2001; Schmitt et al., 2010; van de Graaf et al., 2014). In our study all questions had factor loadings of $>0.4$, except item \#6 ("for the past four weeks has your knee locked or caught?"). Previous studies (Irrgang et al., 2001; Schmitt et al., 2010; Higgins et al., 2007) which also have reported a lower loading for item \#6, performed their factor analysis in a population with "various knee disorders". The population in our study includes patients at six to eight months after ACL reconstruction, where "locking" or "catching" is not typically a problem (in contrast with meniscal injuries). The lower loading 
value of item \#6 might suggest that this item may be less relevant for an $A C L$ reconstruction population, something that is supported by the fact that item \#6 was rated as not relevant by experts in the field and patients with an acute ACL injury (van Meer et al., 2013). In addition, since previous studies of the measurement properties of the IKDC-SKF generally show a low loading value for item \#6, it might suggest that the question does not entirely reflect the same construct as the remaining 17 questions.

The highest correlation at hypothesis testing was between the IKDC-SKF and the KOOS subscale "function, sports and recreational activities". This fits with the fact that the IKDCSKF is designed to evaluate patient-reported symptoms during physical activity. Overall, the correlation to KOOS subscales was high, compared to the correlation to ACL-RSI or the question of satisfaction with knee function. Taken together, these findings might suggest that the IKDC-SKF and KOOS measure similar constructs. When comparing the two questionnaires, the IKDC-SKF has less respondent burden than the KOOS and has a simple method for calculation of the total score. Previous studies indicate that IKDC-SKF may have superior validity, reliability and responsiveness than KOOS early after ACL injury, after $A C L$ reconstruction, and before or after meniscal surgery (van de Graaf et al., 2014; van Meer et al., 2013).

The IKDC-SKF is responsive when measuring patient-reported changes over time in the rehabilitation process after an ACL reconstruction. This is evident in the value of AUC, the confirmed hypothesis for construct testing, the high effect size and high standardized response means. The result of our responsiveness testing supports previous reports of good responsiveness (Greco et al., 2010; van Meer et al., 2013). 
The floor and ceiling effect was below 15\%, which is in line with previous studies (Irrgang et al., 2001; Bjorklund et al., 2009; Crawford et al., 2007; Haverkamp et al., 2006; Kocher et al., 2011; Metsavaht et al., 2010; Padua et al., 2004).

\section{Limitations}

One limitation could be the use of the SF36 as a gold standard to IKDC-SKF, since the SF36 is not a knee injury-specific questionnaire. However it may be difficult to find an optimal gold standard for patient-reported outcomes. Often the gold standard used is one that has been accepted as a gold standard by experts in the field (de Vet et al., 2011). Our decision to use the SF36 as gold standard for construct validity was based on the fact that the SF36 was used as the criterion in the original version of the IKDC-SKF (Irrgang et al., 2007).

Our decision to include patients who were "somewhat improved but not fully recovered" in "no change" group for responsiveness analysis (ROC curve) was based on the fact that patients might overestimate their progress to "please" the caregivers (de Vet et al., 2011). It was corroborated by the fact that those who reported "somewhat improved but not fully recovered" had a lower mean change score of the IKDC-SKF from baseline to 4 months than the $\mathrm{SDC}_{\text {group }}$ value or the MCID, suggesting that there was no clinically significant improvement in state.

\section{Perspective}

The IKDC-SKF is the most commonly used patient-reported outcome after ACL injury (Wera et al., 2014). Our study adds knowledge about the measurement properties of the IKDC-SKF: we found that the Swedish version of the IKDC-SKF is valid, reliable and responsive. We also provide important information about the interpretability of the scale; the MCID and floor and ceiling effect both before $\mathrm{ACL}$ reconstruction and at several clinically-relevant time 
points during $A C L$ reconstruction rehabilitation. The use of a well-designed patient reported outcome measurement instrument leads to extended possibilities to compare scientific data worldwide, and is important for quality clinical practice.

\section{Conclusion}

The Swedish version of the IKDC-SKF had good measurement properties in a population of ACL deficient patients undergoing $\mathrm{ACL}$ reconstruction.

\section{Acknowledgement}

The authors acknowledge Eva Ageberg, Magnus Forssblad, Jon Karlsson, Ninni Sernert and Suzanne Werner for their kind contribution as expert panel in the translation process. 


\section{References}

Beaton DE. Understanding the relevance of measured change through studies of responsiveness Spine 2000: 25: 3192-3199.

Björklund K, Andersson L, Dalen N. Validity and responsiveness of the test of athletes with knee injuries: the new criterion based functional performance test instrument Knee Surg Sports Traumatol Arthrosc 2009: 17: 435-445.

Crawford K, Briggs K K, Rodkey WG, Steadman JR. Reliability, validity, and responsiveness of the IKDC score for meniscus injuries of the knee. Arthroscopy 2007: 23: 839-844.

De Vet HCW, Terwee CB, Mokkink LB, Knol DL. Measurement in medicine. Cambridge: New York, Cambridge University Press; 2011: 206-215, 159-163.

Fluss R, Faraggi D, Reiser B. Estimation of the Youden Index and its associated cutoff point. Biom J 2005: 47: 458-472.

Greco NJ, Anderson AF, Mann BJ, Cole BJ, Farr J, Nissen CW, Irrgang, JJ. Responsiveness of the International Knee Documentation Committee Subjective Knee Form in comparison to the Western Ontario and McMaster Universities Osteoarthritis Index, modified Cincinnati Knee Rating System, and Short Form 36 in patients with focal articular cartilage defects. Am J Of Sports Med 2010: 38: 891-902.

Grevnerts HT, Terwee CB, Kvist J. 2014. The measurement properties of the IKDC-subjective knee form. Knee Surg Sports Traumatol Arthrosc 2014: Epub ahead of print [PMID: 25193574].

Guillemin F, Bombardier C, Beaton D. Cross-cultural adaptation of health-related quality of life measures: literature review and proposed guidelines. J Clin Epidemiol 1993: 46: 1417-1432.

Haverkamp D, Sierevelt I N, Breugem SJ, Lohuis K, Blankevoort L, Van Dijk CN. Translation and validation of the Dutch version of the International Knee Documentation Committee Subjective Knee Form. Am J Sports Med 2006: 34: 1680-1684. 
Higgins LD, Taylor MK, Park D, Ghodadra N, Marchant M, Pietrobon R, Cook C. Reliability and validity of the International Knee Documentation Committee (IKDC) Subjective Knee Form. Joint Bone Spine. 2007: 74: 594-599.

Hopkins WG. Measures of reliability in sports medicine and science. Sports Med 2000: 30: 1-15. Irrgang JJ, Andersson AF, Boland AL, Harner CD, Kurosaka M, Neyret P, Richmond JC, Shelborne KD. Development and validation of the international knee documentation committee subjective knee form. Am J of Sports Med 2001: 29: 600-613.

Kamper SJ, Maher CG, Mackay G. 2009. Global rating of change scales: a review of strengths and weaknesses and considerations for design. J of Man Manip Ther 2009: 17: 163-170.

Kline RB. 1999. Nunnally JC, Bernstein IH. (1994). Psychometric theory (3rd ed.). J of Psychoedu Assess: 17: 275-280.

Kocher MS, Smith JT, Iversen MD, Brustowicz K, Ogunwole O, Andersen J, Yoo WJ, McFeely ED, Anderson AF, Zurakowski D. Reliability, validity, and responsiveness of a modified International Knee Documentation Committee Subjective Knee Form (Pedi-IKDC) in children with knee disorders. Am J Sports Med 2011: 39: 933-939.

Kvist J, Osterberg A, Gauffin H, Tagesson S, Webster K, Ardern C. 2012. Translation and measurement properties of the Swedish version of ACL-Return to Sports after Injury questionnaire. Scand J Med Sci Sports 2012: 5: 568-575.

Metsavath L, Leporace G, Riberto M, De Mello Sposito M M, Batista LA. Translation and cross-cultural adaptation of the Brazilian version of the International Knee Documentation Committee Subjective Knee Form: validity and reproducibility. Am J Sports Med 2010: 38: 1894-1899. Mohtadi N. Development and validation of the quality of life outcome measure (questionnaire) for chronic anterior cruciate ligament deficiency. Am J Sports Med 1998: 26: 350-359.

Mokkink L, Terwee C, Knol D, Alonso J, Patrick D, Stratford B, Bouter L, De Vet H. Protocol of the COSMIN study: COnsensus-based Standards for the selection of healthMeasurement INstruments. BMC Med Res Methodol 2006: 6: 1-7 
Mokkink LB, Terwee CB, Patrick DL, Alonso J, Stratford PW, Knol DL, Bouter LM, De Vet HC. The COSMIN study reached international consensus on taxonomy, terminology, and definitions of measurement properties for health-related 538 patient-reported outcomes. J Clin Epidemiol. 2010: 63: 737-745.

Padua R, Bondi R, Ceccarelli E, Bondi L, Romanini E, Zanoli G, Campi, S. Italian version of the International Knee Documentation Committee Subjective Knee Form: cross-cultural adaptation and validation. Arthroscopy 2004: 20: 819-823.

Persson LO, Karlsson J, Bengtsson C, Steen B, Sullivan M. The Swedish SF-36 Health Survey II. Evaluation of clinical validity: results from population studies of elderly and women in Gothenborg. J Clin Epidemiol 1998: 51: 1095-1103.

Roos EM, Toksvig- Larsen S. Knee injury and Osteoarthritis Outcome Score (KOOS) - validation and comparison to the WOMAC in total knee replacement. Health Qual Life Outcomes 2003: 1: 17.

Schmitt LC, Paterno MV, Huang S. Validity and internal consistency of the international knee documentation committee subjective knee evaluation form in children and adolescents. Am J Sports Med 2010: 38: 2443-2447.

Sullivan M, Karlsson J. The Swedish SF-36 Health Survey III. Evaluation of criterion-based validity: results from normative population. J Clin Epidemiol 1998: 51: 1105-1113.

Sullivan M, Karlsson J, Ware JE, Jr. The Swedish SF-36 Health Survey--I. Evaluation of data quality, scaling assumptions, reliability and construct validity across general populations in Sweden. Soc Sci Med (1982) 1995: 41: 1349-1358.

Terwee CB, Bot SD, De Boer MR, Van Der Windt DA, Knol DL, Dekker J, Bouter LM, De Vet HC. Quality criteria were proposed for measurement properties of health status questionnaires. J Clin Epidemiol 2007: 60: 34-42. 
Van De Graaf VA, Wolterbeek N, Scholtes VA, Mutsaerts EL, Poolman RW. Reliability and Validity of the IKDC, KOOS, and WOMAC for Patients With Meniscal Injuries. Am J Sports Med 2014: 42: $1408-1416$.

Van Meer BL, Meuffels DE, Vissers MM, Bierma- Zeinstra SM, Verhaar JA, Terwee CB., Reijman M. Knee injury and Osteoarthritis Outcome Score or International Knee Documentation Committee Subjective Knee Form: which questionnaire is most useful to monitor patients with an anterior cruciate ligament rupture in the short term? Arthroscopy 2013: 29: 701-715.

Wang YC, Hart DL, Stratford PW, Mioduski JE. Baseline dependency of minimal clinically important improvement. Phys Ther 2011: 91: 675-688.

Wera JC, Nyland J, Ghazi C, Mackinlay KG, Henzman RC, Givens J, rand JC. International knee documentation committee knee survey use after anterior cruciate ligament reconstruction: a 2005-2012 systematic review and world region comparison. Arthroscopy 2014: 30: 15051512.

Wright A, Hannon J, Hegedus EJ, Kavchak AE. Clinimetrics corner: a closer look at the minimal clinically important difference (MCID). J Man Manip Ther. 2012: 20: 160-66.

Youden W. Index for rating diagnostic tests. Cancer 1950:3: 32-35. 
Table 1. The IKDC results and timing of each measurement.

\begin{tabular}{llllll}
\hline $\begin{array}{l}\text { Measurement } \\
\text { occasion }\end{array}$ & $\mathbf{n}$ & $\begin{array}{l}\text { Timing of } \\
\text { measurement* } \\
\text { mean(range) days }\end{array}$ & $\begin{array}{l}\text { IKDC score } \\
\text { mean(SD) }\end{array}$ & $\begin{array}{l}\text { IKDC score } \\
\text { min-max }\end{array}$ & $\begin{array}{l}\text { 95\% Confidence } \\
\text { Interval for } \\
\text { mean }\end{array}$ \\
\hline Baseline & 76 & $11(0-65)$ & $51.1(16.2)$ & $12.6-80.5$ & $47.4-54.8$ \\
$4 \mathrm{~m}$ & 55 & $115(87-167)$ & $57.6(15.3)$ & $14.9-82.8$ & $49.7-59.3$ \\
$6-8 \mathrm{~m}^{* *}$ & 249 & $201(153-333)$ & $70.2(17.2)$ & $9.2-100$ & $67.9-72.3$ \\
$12 \mathrm{~m}$ & 50 & $384(353-743)$ & $78.1(16.6)$ & $31.0-98.9$ & $70.2-82.2$ \\
\hline
\end{tabular}

* Number of days prior to $A C L$ reconstruction for the Baseline evaluation, and number of days after the $A C L$ reconstruction for all the other measurement occasions.

** Participants recruited from orthopaedic clinics $(n=46)$ and the Swedish National Registry $(n=203)$ 
Table 2. Patient Reported Outcome Measures (PROMs) scores at baseline (before ACL reconstruction) and at each measurement occasion after $\mathrm{ACL}$ reconstruction, used in the validation process of the Swedish IKDC subjective knee Form.

\begin{tabular}{|c|c|c|c|c|}
\hline $\begin{array}{l}\text { Patient reported } \\
\text { outcome }\end{array}$ & $\begin{array}{l}\text { Baseline } \\
\text { Mean (SD) 95\% Cl }\end{array}$ & $\begin{array}{l}4 \text { months } \\
\text { Mean (SD) } 95 \% \mathrm{Cl}\end{array}$ & $\begin{array}{l}\text { 6-8 months } \\
\text { Mean (SD) } 95 \% \mathrm{Cl}\end{array}$ & $\begin{array}{l}12 \text { months } \\
\text { Mean (SD) 95\% Cl }\end{array}$ \\
\hline KOOS "symptoms" & $\begin{array}{l}69.1(19.8) 60.9- \\
74.0\end{array}$ & $\begin{array}{l}68.4(18.8) 64.5- \\
75.7\end{array}$ & 76.1 (18.6) 73.2-78 & 80.5 (17) 77.7-86.4 \\
\hline KOOS"pain" & $\begin{array}{l}72.5(18.8) 64.6- \\
77.2\end{array}$ & 77.8 (16.8) 71-82 & $84.2(14.9) 82-85.8$ & 87.5 (13.7) 83.1-92 \\
\hline $\begin{array}{l}\text { KOOS "function and } \\
\text { daily living" }\end{array}$ & $\begin{array}{l}83(17.4) 75.3- \\
87.8\end{array}$ & $\begin{array}{l}89.3(14.3) 84.5- \\
48.3\end{array}$ & 93.1 (10.7) 91.7-94.4 & $94.2(10.1) 92-98.1$ \\
\hline $\begin{array}{l}\text { KOOS "function, } \\
\text { sports and } \\
\text { recreational activities" }\end{array}$ & $\begin{array}{l}41.5(28.9) 28.4- \\
48.1\end{array}$ & $\begin{array}{l}42.3(26.8) 32.2- \\
48.3\end{array}$ & $64.5(25.8) 60.6-67.2$ & 70.5 (25.7) 59.9-76.9 \\
\hline KOOS "quality of life" & $\begin{array}{l}29.5(17) 21.1- \\
31.8\end{array}$ & $\begin{array}{l}42.3(20.1) 35.5- \\
48.6\end{array}$ & 55.5 (21.2) 52.5-58 & $63.8(22.5) 54.6-68.8$ \\
\hline ACL-RSI & Not tested & Not tested & Not tested & 6 (2.3) 5.1-6.6 \\
\hline SF36; PCS & $\begin{array}{l}41.7(8.6) 38.1- \\
43.3\end{array}$ & 44 (9.3) 40.9-46.3 & 48 (7.9) 47-49 & 49.8 (9) 47.8-53.2 \\
\hline SF36; MCS & $\begin{array}{l}45.2(12.3) 41.7- \\
49.1\end{array}$ & $\begin{array}{l}45.8(11.8) 41.4- \\
49.3\end{array}$ & $48(9.4) 46.8-49.3$ & $49.2(10.1) 45.2-51.7$ \\
\hline
\end{tabular}


Table 3. Hypotheses and the results from the statistical testing

Hypothesis including the a priori estimated

Measurement $r$

$\mathbf{P}$

magnitude of correlation occasion

1. Patients who were satisfied with their current knee function scores higher on the IKDC-SKF than those 6 and 8

$0.79<0.001$ who were not $(r>0.5)$.

2. Patients who reported they would be highly months satisfied with living with their current knee function, for the rest of their lives scores higher on the IKDCSKF than those who reported they would not $(r>0.5)$.

3. Patients who scored high on the KOOS subscale "symptoms" would score high on the IKDC-SKF ( $r>$ 6 and 8 $0.74<0.001$ $0.5)$.

4. Patients who scored high on the KOOS subscale months "pain" would score high on the IKDC-SKF $(r>0.5)$ 6 and 8

$0.82<0.001$

5. Patients who scored high on the KOOS subscale months "function, daily living" would score high on the IKDC- months SKF $(r>0.5)$.

6. Patients who scored high on the KOOS subscale "function, sports and recreational activities" would score high on the IKDC-SKF $(r>0.5)$.

7. Patients who scored high on the KOOS subscale "quality of life" would score high on the IKDC-SKF ( $r>$ $0.5)$.

8. Patients who scored high on the ACL-RSI would 12 months $\quad 0.69<0.001$ scores high on the IKDC-SKF $(r>0.5)$.

\begin{tabular}{lllll}
\hline $\begin{array}{l}\text { 9. Patients who estimated their knee stability as high } \\
\text { in activities of daily living would score high on the }\end{array}$ & $\begin{array}{l}6 \text { and } 8 \\
\text { months }\end{array}$ & 0.69 & $<0.001$ \\
IKDC-SKF $(r>0.5)$. & & & \\
\hline $\begin{array}{l}\text { 10. Patients who estimated their knee stability as high } \\
\text { in exercise and sports would score high on the IKDC- }\end{array}$ & $\begin{array}{l}6 \text { and } 8 \\
\text { months }\end{array}$ & 0.71 & $<0.001$ \\
SKF $(r>0.5)$. & & &
\end{tabular}

IKDC-SKF = International Knee Documentation Committee Subjective Knee Score, KOOS= Knee injury and osteoarthritis outcome score, $\mathrm{ACL}-\mathrm{RSI}=\mathrm{ACL}-$ return to sport after injury scale. 
Table 4. The answering rates for the different categories of the GRC and the change score of the IKDC-SKF from baseline to 4 months.

\begin{tabular}{|c|c|c|}
\hline Answer GRC & n & $\begin{array}{l}\text { Change score of the } \\
\text { IKDC-SKF mean(SD) }\end{array}$ \\
\hline "Fully recovered" & 0 & \multirow[b]{2}{*}{$16.2(14.8)$} \\
\hline $\begin{array}{l}\text { "Great improvement but } \\
\text { not fully recovered" }\end{array}$ & 23 & \\
\hline $\begin{array}{l}\text { "Somewhat improved but } \\
\text { not fully" recovered }\end{array}$ & 24 & \multirow[t]{2}{*}{$0.3(12.4)$} \\
\hline "Unchanged" & 0 & \\
\hline
\end{tabular}

GRC=Global rating of change, IKDC-SKF=International Knee Documentation Committee Subjective Knee Form, SD=standard deviation 
Table 5. Hypotheses and the result from statistical testing for responsiveness testing

\begin{tabular}{|c|c|c|}
\hline $\begin{array}{l}\text { Hypothesis for responsiveness of change } \\
\text { including the á priori estimated magnitude } \\
\text { of correlation }\end{array}$ & $\begin{array}{l}\text { Correlation in change } \\
\text { between Baseline and } 4 \\
\text { months }(n=55)(p)\end{array}$ & $\begin{array}{l}\text { Correlation in change } \\
\text { between Baseline and } \\
12 \text { months }(n=50)(p)\end{array}$ \\
\hline $\begin{array}{l}\text { 1.The change in KOOS subscale "symptoms" } \\
\text { would correlate to the change in IKDC-SKF } \\
(r>0.5)\end{array}$ & $0.54(<0.01)$ & $0.57(<0.01)$ \\
\hline $\begin{array}{l}\text { 2.The change in KOOS subscale "pain" } \\
\text { would correlate to the change in IKDC-SKF } \\
(r>0.5)\end{array}$ & $0.74(<0.01)$ & $0.72(<0.01)$ \\
\hline $\begin{array}{l}\text { 3. The change in KOOS subscale "function, } \\
\text { daily living" would correlate to the change } \\
\text { in IKDC-SKF }(r>0.5)\end{array}$ & $0.59(<0.01)$ & $0.57(<0.01)$ \\
\hline $\begin{array}{l}\text { 4.The change in KOOS subscale "function, } \\
\text { sports and recreational activities" would } \\
\text { correlate to the change in IKDC-SKF ( }>0.5)\end{array}$ & $0.77(<0.01)$ & $0.68(<0.01)$ \\
\hline $\begin{array}{l}\text { 5.The change in KOOS subscale "quality of } \\
\text { life" would correlate to the change in IKDC- } \\
\text { SKF ( } r>0.5)\end{array}$ & $0.71(<0.01)$ & $0.66(<0.01)$ \\
\hline $\begin{array}{l}\text { 6. The change in SF- } 36 \text { PCS would correlate } \\
\text { to the change in IKDC-SKF }(r>0.5)\end{array}$ & $0.58(<0.01)$ & $0.52(<0.01)$ \\
\hline
\end{tabular}




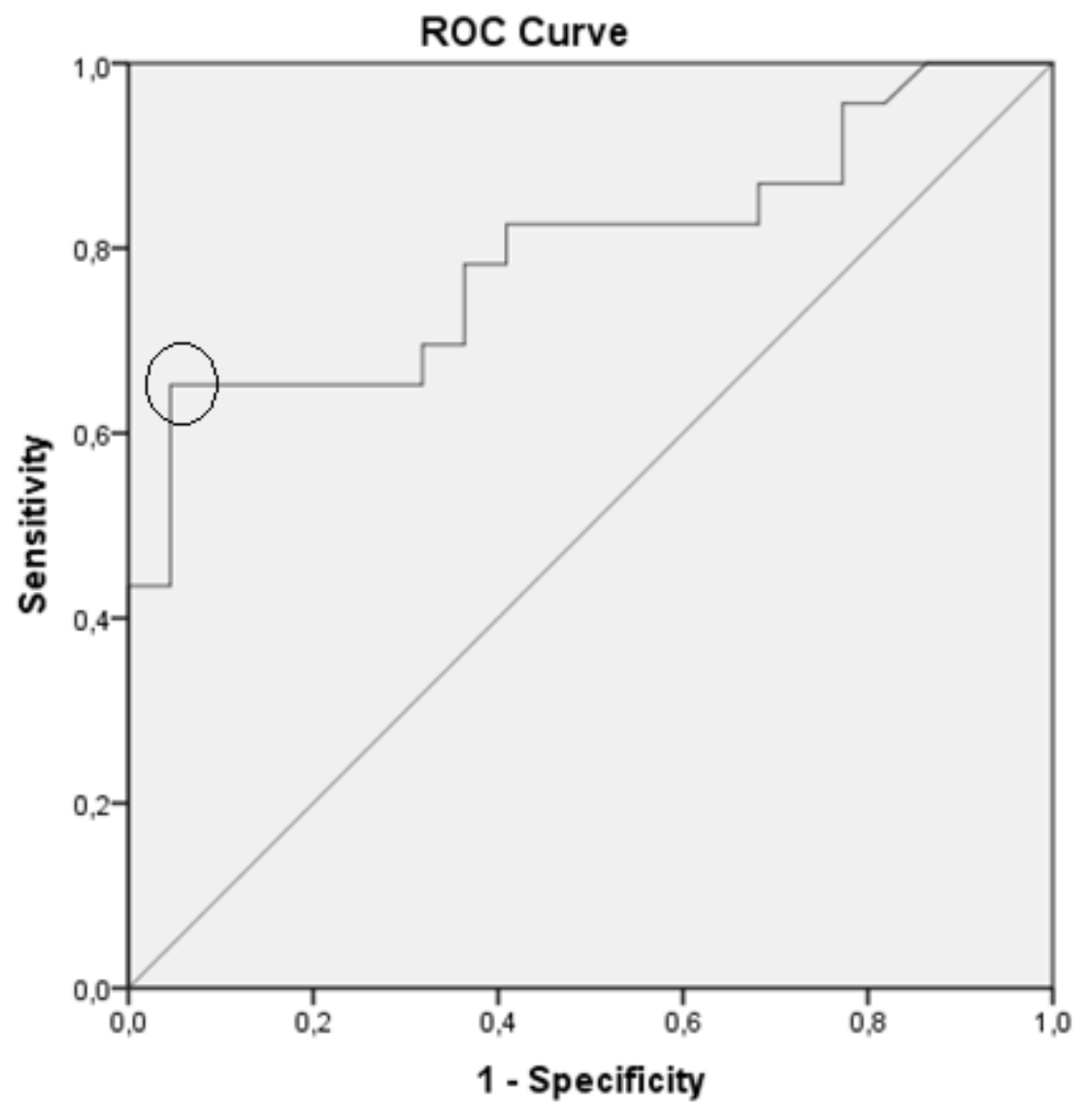

Fig 1. The ROC analysis of patient data from baseline to 4 months, showing an AUC of 0.79 and the point with the highest sensitivity and specificity marked by a ring. 